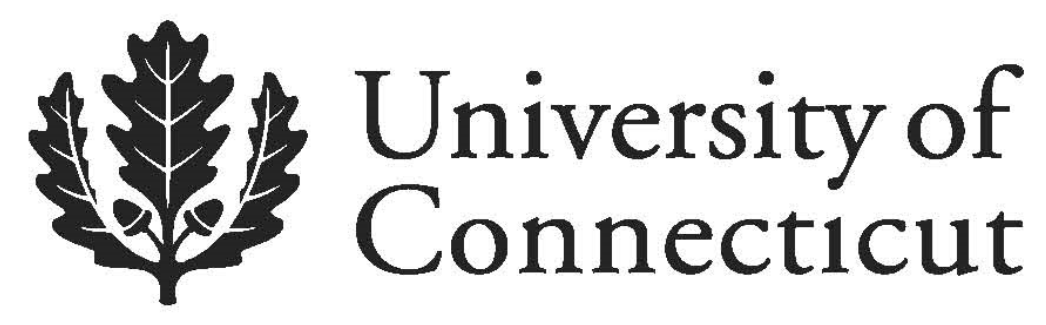

Department of Economics Working Paper Series

Temporal Causality between House Prices and Output in the U.S.:

A Bootstrap Rolling-Window Approach

Wendy Nyakabawo

University of Pretoria

Stephen M. Miller

University of Nevada, Las Vegas

University of Connecticut

Mehmet Balcilar

Eastern Mediterranean University

Sonali Das

Council for Scientific and Industrial Research

Rangan Gupta

University of Pretoria

Working Paper 2013-14

June 2013

365 Fairfield Way, Unit 1063

Storrs, CT 06269-1063

Phone: (860) 486-3022

Fax: (860) 486-4463

http://www.econ.uconn.edu/

This working paper is indexed on RePEc, http://repec.org 


\title{
Temporal Causality between House Prices and Output in the U. S.: A Bootstrap Rolling-Window Approach
}

\author{
Wendy Nyakabawo \\ Department of Economics, University of Pretoria \\ Pretoria, 0002, SOUTH AFRICA \\ Stephen M. Miller* \\ Department of Economics, University of Nevada, Las Vegas \\ Las Vegas, Nevada, 89154-6005 USA \\ e-mail: stephen.miller@unlv.edu \\ Mehmet Balcilar \\ Department of Economics, Eastern Mediterranean University \\ Famagusta, NORTHERN CYPRUS, \\ via Mersin 10, TURKEY \\ Sonali Das \\ Council for Scientific and Industrial Research (CSIR) \\ Pretoria, SOUTH AFRICA \\ Rangan Gupta \\ Department of Economics, University of Pretoria \\ Pretoria, 0002, SOUTH AFRICA
}

\begin{abstract}
This paper examines the causal relationships between the real house price index and real GDP per capita in the U.S., using the bootstrap Granger (temporal) non-causality test and a fixed-size rolling-window estimation approach. We use quarterly time-series data on the real house price index and real GDP per capita, covering the period 1963:Q1 to 2012:Q2. The full-sample bootstrap non-Granger causality test result suggests the existence of a unidirectional causality running from the real house price index to real GDP per capita. A wide variety of tests of parameter constancy used to examine the stability of the estimated vector autoregressive (VAR) models indicate short- and long-run instability. This suggests that we cannot rely on the full-sample causality tests and, hence, this warrants a time-varying (bootstrap) rolling-window approach to examine the causal relationship between these two variables. Using a rolling window size of 28 quarters, we find that while causality from the real house price to real GDP per capita occurs frequently, significant, but less frequent, evidence of real GDP per capita causing the real house price also occurs. These results imply that while the real house price leads real GDP per capita, in general (both during expansions and recessions), significant feedbacks also exist from real GDP per capita to the real house price.
\end{abstract}

Keywords: Real house price, Real GDP per capita, Bootstrap, Time-Varying Causality.

JEL Classifications: C32, E32, R31

* $\quad$ corresponding author 


\section{Introduction}

This paper investigates the temporal (Granger) causal relationship, if any, between the real house price index and real GDP per capita, using bootstrap full- and sub-sample rollingwindow estimation for the U.S. economy. Empirical studies that examine the causal relationships between variables may suffer from inaccurate findings from full-sample timeseries data, when the data series experience structural changes (Balcilar et al., 2010). In the presence of structural change, the dynamic links between series can exhibit instability across different sub-samples (Balcilar et al., 2010). As such, this paper analyzes whether a temporal (Granger) causal relationship exists between the real house price index and real GDP per capita in the U.S. economy.

We utilize time-varying (28-quarter rolling window) bootstrap causality tests between the real house price and real GDP per capita, over the period 1963:Q1 to 2012:Q2. This sample period covers a series of different economic expansions and recessions in the U.S, as well as different market booms and busts, creating substantial volatility, that may provide different outcomes from other less-volatile periods (Iacoviello and Neri, 2010). We test the stability of the short- and long-run relationships between the two series to assess the reliability of full-sample causality tests. The U.S case provides an interesting case study, because of the important role the housing sector played historically, including during the recent global financial crisis and Great Recession. For example, Leamer (2007) and Bernanke (2008) argue that weaknesses in the housing sector exert a pivotal role in the U.S business cycle.

This paper contributes to the existing literature by considering the possibility of structural change. That is, we allow the temporal (Granger) causal relationship between the real house price index and real GDP per capita to vary over time, instead of assuming 
structural stability within the full sample period. We implement bootstrap Granger noncausality tests for a series of rolling-window sub-sample estimations.

The subprime mortgage lending fiasco and the financial crisis sparked a price bubble and collapse in the housing market and the subsequent Great Recession. Many economists argue that these events caused the recent dramatic changes in the behavior of financial and economic markets (Miller et al., 2011), even extending to global financial markets and economies. A growing literature recognizes the importance of the relationship between the housing market and the macro economy, showing that the interaction between house prices and economic growth imbeds important policy implications. Economists and policy makers seemingly agree that house prices play an important role in stimulating the growth or decline of an economy. Miller et al., (2011) suggest that the strong housing market during the 2001 stock market crash may have saved the U.S. economy from a severe recession and that, in addition, the recent collapse of the housing market initiated he Great Recession. The housing market, thus, plays an important role in the economy and its performance affects its overall performance. $^{1}$

Several economic theories identify how house price adjustments affect the economy. Much of this literature focuses on the wealth and collateral effects of house price changes on consumption (Miller et al., 2011). Changes in house prices can affect consumption, if households regard the equity in their property as wealth and their spending decisions respond to their net wealth. The permanent income hypothesis suggests that housing equity can produce a wealth effect, where unanticipated increases in house prices increase homeowners' expected lifetime wealth. The increase in lifetime wealth leads individuals to increase their desired consumption, because of the consumption smoothing motive (Miller et al., 2011).

\footnotetext{
${ }^{1}$ Other views of the causes of the business cycle exist. Hamilton (2003, 2009) argues that oil price shocks proximately causes of post-WWII recessions in the US.
} 
House prices can also affect consumption of liquidity constrained households, since their access to credit depends partly on their housing equity. That is, since the households' ability to borrow depends on the collateralized value of exiting assets, households can increase borrowing secured on rising property values, thus relaxing their financial constraints. Part of the rise in housing equity may then finance extra consumption (Girouard et al., 2006). This collateral effect appears in a number of studies on the effect of house price changes on consumption (Aoki, et al., 2004; Buiter, 2008; Lustig and van Niewerburg, 2008).

The nature and direction of causality between house price and economic fundamentals can differ widely depending on the period examined and the methodology used. Although a number of studies examine the spillover effects of the real house price onto consumption in the U.S (e.g., Green, 1997; Belsky and Prakken, 2004; Carroll, 2004; Iacoviello, 2005, 2010, 2011; Case et al., 2005, 2013; Campbell and Cocco, 2007; Leamer, 2007; Iacoviello and Neri, 2010; Carroll et al., 2011; Mian and Sufi, 2011; Midrigan and Philippon, 2011; Abdallah and Lastrapes, 2012; Mian et al., 2012; Zhou and Carroll, 2013; Guerrieri and Iacoviello, 2013; Liu et al., 2013 and references cited there in), only two, to the best of our knowledge, consider the relationship between house prices and output (Demary, 2010; Miller et al., 2011). Demary (2010) investigates the link between the real house price and key macroeconomic variables, including output, for ten OECD countries, including the U.S, and concludes that the real house price significantly affects output. Using quarterly data for all 379 metropolitan statistic areas (MSAs) in the U.S. from 1980:1 to 2008:2, Miller et al., (2011) empirically study the effect of house prices on local Gross Metropolitan Product (GMP). The paper concluded that house price changes significantly affect GMP growth, and the effect of predictable changes (the collateral effect) generate about three times the effect of 
unpredictable changes (the wealth effect). ${ }^{2}$ Neither of these two papers, however, considers the time-varying nature of the causal relationship between house prices and economic growth.

Our paper considers the time-varying nature of the relationship, if any, between the real house price index and real GDP per capita over 1963:Q1 to 2012:Q2, using the bootstrap Granger (temporal) non-causality test and a fixed-size rolling-window estimation approach. The full-sample bootstrap non-Granger causality test implies unidirectional causality from the real house price index to real GDP per capita. Several tests of parameter constancy indicate short- and long-run instability. Using a rolling window size of 28 quarters, we find that while the real house price leads real GDP per capita, in general (both during expansions and recessions), significant feedbacks also exist from real GDP per capita to the real house price.

The rest of the paper is organized as follows: Section 2 outlines the methodology. Section 3 describes the data. Section 4 discusses the empirical results. Section 5 concludes.

\section{Method}

Following Balcilar et al., (2010), this paper analyzes temporal (Granger) causality between the real house price index and real GDP per capita, using the vector autoregressive (VAR) framework. We use the Granger non-causality method to determine whether one time series significantly forecasts another (Granger, 1969). A variable $x$ does not Granger cause another variable $y$, if lagged values of variable $x$ do not provide significant additional explanatory power in predicting $y$, after controlling for lagged values of $y$. The Granger non-causality hypothesis tests a joint restriction, using the Wald, Lagrange multiplier (LM), and likelihood ratio $(L R)$ statistics. These test statistics require stationary time series. If stationarity does not hold, then the time series may not exhibit standard asymptotic distributions, causing

\footnotetext{
${ }^{2}$ Interestingly, an earlier version of this paper carried out formal Granger causality tests in a panel VAR set-up for the 379 MSAs, concluding unidirectional causality running from GMP to house prices. The working paper version is available at: www.sandiego.edu/business/.../HousePricesandEconomicGrowth.pdf.
} 
difficulties in the levels estimation of VAR models (Sims, Stock and Watson, 1990 and Toda and Phillips 1993, 1994).

To overcome these difficulties, Toda and Yamamoto (1995) propose a simple solution to obtain standard asymptotic distribution for the Wald test by estimating an augmented VAR with $I(1)$ variables, or the long-run causality test of $\operatorname{VAR}(p)$ coefficients. The procedure requires at least one unrestricted coefficient matrix under the null hypothesis to generate standard asymptotic distribution. Shukur and Mantalos (1997b) use Monte Carlo simulations to investigate the size and power properties of eight different versions of the Granger noncausality test in standard and modified form, including the modified Wald test proposed by Toda and Yamamoto (1995). The results show that the Wald test does not possess the correct size in small- and medium-sized samples. Furthermore, results from Shukur and Mantalos (1997a) illustrate that the critical values may improve by applying the residual-based bootstrap (RBB) method, so that the true size of the test in a system of one to ten equations approaches its nominal value (Balcilar et al., 2010). Moreover, evaluation of properties of the RBB method in VAR systems with cointegrated time series establishes robust RBB critical values when compared to asymptotic ones (Mantalos and Shukur, 1998). Shukur and Mantalos (2000) prove that small sample corrected LR tests exhibit relatively better power and size properties, even in small samples. Their results, however, indicate that in the absence of cointegration, all standard tests that do not use the RBB method perform inadequately, particularly in small samples. A comparison of the properties of the bootstrap, Wald and corrected LR tests in cointegrated and non-cointegrated processes show that the bootstrap test possesses the best power and size in almost all situations, regardless of cointegration properties (Mantalos, 2000). Moreover, Hacker and Hatemi-J (2006) confirm that the modified Wald test based on a bootstrap distribution exhibits smaller size distortions irrespective of sample sizes, integration orders, and error-term processes (Balcilar et al., 
2010). Therefore, based on these findings, this paper uses the RBB based modified-LR statistic to examine the causality between the real house price index and real GDP per capita in the U.S., because this method applies to cointegrated and non-cointegrated I(1) variables (Hacker and Hatemi-J, 2006).

Consider the following bivariate $\operatorname{VAR}(p)$ process:

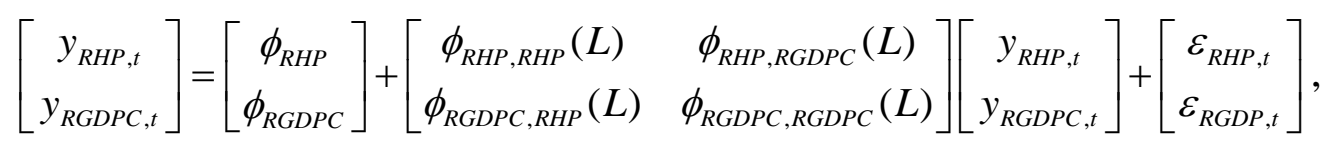

where $y_{R H P, t}$ and $y_{R G D P C, t}$ represents the natural logarithms of the real house price index (RHP) and real GDP per capita (RGDPC), respectively, $\phi_{i j}(L)=\sum_{k=1}^{p+1} \phi_{i j, k} L^{k}, i, j=1,2$, where $L$ is the lag operator defined as $L^{k} x_{t}=x_{t-k}$, and $\varepsilon_{R H P, t}$ and $\varepsilon_{R G D P C, t}$ are zero-mean, independent, white-noise processes with non-singular covariance matrix $\sum$. Now, we determine the optimal lag length $p$, using the Schwarz Information Criteria (SIC).

Given equation (1), we test the causality relationship between the real house price index and real GDP per capita, by imposing restrictions on the coefficients. That is, imposing zero restriction $\phi_{12, i}=0$ for $i=1,2, \ldots, p$, we can test the null hypothesis that real GDP per capita does not Granger cause the real house price. Imposing the restriction that $\phi_{21, i}=0$ for $i=1,2, \ldots, p$ tests the null hypothesis that the real house price does not Granger cause real GDP per capita. The direction and sign of causality between the real house price and real GDP per capita possess important policy implications. If a unidirectional causality exists from the real house price to real GDP per capita, then movements in the real house price help to forecast real GDP per capita. Policies that bring about stability in the real house price will probably help to stabilize real GDP per capita. Furthermore, policies that depress the housing market will probably depress output while policies that stimulate the housing market will probably stimulate output (Chui and Chau, 2005; and Simo-Kengne et al., 2012). 
Common to many other testing conditions, Granger non-causality tests assume that the parameters of the VAR model used in testing remain constant over time. Structural changes, however, often violate this assumption. Granger (1996) emphasizes the issue of parameter non-constancy as one of the most challenging issues facing recent empirical analyses. Researchers can identify and incorporate the presence of structural changes into the estimation using techniques such as sample splitting and dummy variables. These techniques, however, introduce pre-test bias. Therefore, to overcome the parameter non-constancy and avoid pre-test bias, this paper applies the rolling-window bootstrap estimation (Balcilar et al., 2010).

We examine the effect of structural change using rolling-window Granger-causality tests, based on the modified bootstrap test. In the presence of structural change, the dynamic links between the real house price and real GDP per capita will show instability across different sub-samples. We consider this instability by applying the bootstrap causality test to rolling-window sub-samples for $t=\tau-l+1, \tau-l, \ldots, \tau, \tau=l, l+1, \ldots, T$, where $l$ is the size of the rolling window (Balcilar et al., 2010). The rolling-window technique uses a fixed-length moving window sequentially from the beginning to the end of the sample by adding one observation from ahead and dropping one from behind, where each rolling-window subsample includes $l$ observations. In each step, we apply the causality test to each sub-sample, providing a $(T-l)$ sequence of causality tests, as opposed to just one. Two important reasons justify the use of the rolling-window estimation. First, the rolling window adopts the view that the relationship between variables changes through time. Second, we observe instability across different sub-samples due to structural change and the rolling-window estimation captures this process. ${ }^{3}$

\footnotetext{
${ }^{3}$ See results in section 4 .
} 
The rolling-window regression trades off two conflicting objectives - accuracy of the parameter estimates and the representativeness of the model over the subsample period. For example, better accuracy implies more degrees of freedom. But, this implicitly assumes that structural change does not occur within the subsample period. Otherwise, the model cannot represent the entire subsample period. Representativeness improves with a smaller window, since the chances of structural change occurring within the subsample diminishes as the size of the subsample shrinks. Pesaran and Timmerman (2005) shows that a small window size reduces the risk of including multiple shifts in the subsamples. But, the smaller subsample size means that the accuracy of the parameter estimates goes down as the standard errors rise. In sum, a small window size reduces heterogeneity and improves the representativeness of parameters, but may reduce parameter accuracy by increasing the standard errors of estimates. A large window size, on the other hand, may improve the accuracy of estimates, but reduces the representativeness of the model, especially in the presence of heterogeneity.

Therefore, in selecting a window size, we balance the trade-off between representativeness and accuracy. We initially tried window sizes of 20, 28, and 40 quarters or 5, 7, and 10 years, respectively. Qualitatively, the findings do not differ too much across the different widow specifications. Quantitatively, we do see differences. For the smallest (largest) window size of 20 (40), we find the fewest (largest) number of significant effects. We attribute these findings to the less-accurate estimates of the parameters in the smallest window of 20 quarters. In addition, the middle choice of a 28 quarter window generates findings that quantitatively come much closer to the 40-quarter-window findings. Thus, we adopt a middle window size to balance the trade-off between accuracy and the avoidance of heterogeneity problems. To generate parameter estimates and tests with better precision, we further use the bootstrap technique for each subsample estimation. 
Moreover, to consider possible changes in the causality relationships, we estimate the bootstrap $p$-value of observed LR-statistics rolling over the whole sample period 1963:Q1 to 2012:Q2. That is, we estimate the VAR model in equation (1) for a time span of 28 quarters (7 years) rolling through $t=\tau-27, \tau-26, \ldots, \tau$, where $\tau=28, \ldots, T$. We calculate the bootstrap $p$-values of the null hypothesis that real GDP per capita does not Granger cause the real house price (all $\phi_{12, i}=0$ for $i=1,2, \ldots . p$ ) and that the real house price does not Granger cause real GDP per capita (all $\phi_{21, i}=0$ for $i=1,2, \ldots . p$ ), using the RBB method.

Additionally, we investigate the magnitude of the effect of the real house price on real GDP per capita as well as that of real GDP per capita on the real house price. We calculate the effect of the real house price on real GDP per capita as the average of the entire bootstrap estimates using $N_{b}^{-1} \sum_{k-1}^{p} \hat{\phi}_{21, k}^{*}$, where $N_{b}$ equals the number of bootstrap repetitions. For the effect of real GDP per capita on the real house price, $N_{b}^{-1} \sum_{k-1}^{p} \hat{\phi}_{12, k}^{*}$ gives the effect. In these two formula, $\hat{\phi}_{21, k}^{*}$ and $\hat{\phi}_{12, k}^{*}$ equal the bootstrap estimates from the VAR model in equation (1). We calculate the 95-percent confidence interval, and the corresponding lower and upper limits as 2.5 and 97.5 quantiles of each of the $\hat{\phi}_{21, k}^{*}$ and $\hat{\phi}_{12, k}^{*}$, respectively (Balcilar et al., 2010).

To examine the causal relationship between the real house price and real GDP per capita, this paper further applies a bootstrap rolling-window approach in four steps. First, we use the $Z_{\alpha}$ (Phillip and Perron, 1988) and $M Z_{\alpha}$ (Ng-Perron, 2001) unit-root tests to determine whether the two series are stationary. Second, we consider the full-sample temporal (Granger) causality tests. Third, we evaluate the Sup-F, Mean-F, and Exp-F tests, which Andrews (1993) and Andrews and Ploberger (1994) developed, to test parameter stability from the coefficients of the rolling-window VAR regressions. Then, we apply the $L_{c}$ 
test of parameter stability and the Johansen $(1988,1991)$ cointegration test to determine whether a cointegration relationship exists between the series, where we apply the fully modified ordinary least squares (FM-OLS) estimator to test for cointegration. Finally, we estimate the rolling VAR regressions and perform Granger causality tests using a fixed 28 quarter window.

\section{Data}

The data used to analyze the relationship between the real house price and real GDP per capita include four variables -- real GDP, the personal consumption expenditure (PCE) deflator, the civilian non-institutional population, and the Census Bureau constant quality house price index. The study uses quarterly data for the period 1963:Q1 to 2012:Q2. Seasonally adjusted data on real GDP in chained 2005 dollars, the seasonally adjusted chaintype PCE deflator (with a base year of 2005), the seasonally-adjusted house price index on new one-family houses sold including the lot's value (with a base year of 1996) come from U.S Department of Commerce: Bureau of Economic Analysis. ${ }^{4}$ Finally, the population data come from U.S Department of Labor: Bureau of Labor Statistics. We process the data by first converting nominal variables (house price index) into real variables using the PCE deflator (following Rapach and Strauss, 2009) and transforming real GDP into real GDP per capita using the population data. Finally, we transform the real GDP per capita and the real house price index into natural logarithms. Appendix A provides plots of each of the level series. ${ }^{5}$

\footnotetext{
${ }^{4}$ According to Iacoviello and Neri (2010), all available house price indices suffer from some problems. We choose the Census Bureau index because it does not exhibit any upward bias at low frequencies, and also unlike most house price data it comes from one source. In fact, we prefer to use the longest possible house price data from a single source, preventing us from using quarterly data available on the Data segment of Professor Shiller's website that dates back to the first quarter of 1953.

${ }^{5}$ Note that the PCE deflator and population data come at monthly frequencies. We convert them to their quarterly values by taking three-month averages over a specific quarter.
} 


\section{Empirical Results}

We performed the $Z_{\alpha}$ test of Phillip and Perron (1988) and the $M Z_{\alpha}$ unit-root test of NgPerron (2001) to determine whether the real house price and real GDP per capita series of the U.S are stationary. Table 1, Panels A and B report the results of the unit-root tests $Z_{\alpha}$ and $M Z_{\alpha}$, respectively, testing the null hypothesis of non-stationarity (unit root) against the alternative hypothesis of stationarity (no unit root).

According to the results in Table 1 , Panels $\mathrm{A}$ and $\mathrm{B}$, the $Z_{\alpha}$ and $M Z_{\alpha}$ tests fail to reject the null hypothesis of non-stationarity for the real house price and real GDP per capita series at a 5 percent level. The test results further indicate that the first differences of the real house price and real GDP per capita series do reject the null of a unit root. Therefore, the $Z_{\alpha}$ unit root test results indicate that the real house price and real GDP per capita per capita series of the U.S both conform to I(1) processes.

To test the null hypothesis that the real house price does not Granger cause real GDP per capita or real GDP per capita does not Granger cause the real house price, we estimate the full sample bootstrap LR statistics, and their corresponding $p$-values based on the bivariate VAR of real GDP per capita and real house price with lag-length equal to 2, decided based on the Schwarz information criteria (SIC). Table 2 reports the results. We reject the null hypothesis when the $p$-value falls below 0.10 . The results show that we reject the null hypothesis of 'the real house price does not Granger cause real GDP per capita,' but do not reject the null of 'real GDP per capita does not Granger cause the real house price.' Therefore, the results indicate that the real house price temporally (Granger) causes to real GDP per capita, while real GDP per capita does not temporally (Granger) cause the real house price. We, thus, conclude that only one-way causality exits, running from the real house price to real GDP per capita. 
Further, we note that structural changes may shift parameter values and the patterns of (no) cointegration and (no) causal relationships may change over time. That is, structural change may affect the cointegration and temporal (Granger) causality effects, showing sensitivity to sample period adopted. Several tests exist to investigate the stability of VAR models (Andrews and Ploberger, 1994). Problems emerge when the estimated parameters come from unstable relationships that go undetected. The incorrect assumption that such parameter estimates come from stable relationships can produce severe consequences (Hansen, 1992) with severely biased inferences and inaccurate forecasts (Zeileis et al., 2005). Therefore, the researcher must give due consideration the possibility of cointegration between the $I(1)$ variables in the model. For non-cointegrated variables, we can apply the causality test on a standard VAR, where all parameters capture the short-run dynamics and, thus, we only consider the short-run stability of the VAR system (Balcilar et al., 2010). Conversely, for a cointegrated VAR, the variables form a vector error-correction (VEC) model and we must examine the short- and long-run stability of the cointegrated system's parameters. The model will exhibit long-run stability, if the long-run (or cointegrated) parameters prove stable, and will exhibit full structural stability, if the short-run parameters also prove stable.

To examine the temporal stability of the coefficients of the VAR model formed by the real house price and real GDP per capita, we first test the stability of the cointegration parameters. Second, if the long-run parameters prove stable, then we test for the stability of the short-run parameters. To test for parameter stability, we apply the $L_{c}$ tests of Nyblom (1989) and Hansen (1992), which tests the null hypothesis of constant parameters against the alternative hypothesis that the parameters follow a random-walk process, first proposed by Gardner (1969). The $L_{c}$ test can also serve as a test of cointegration, when series are $I(1)$. The F-tests suggested by Andrew (1993) and Andrew and Ploberger (1994) test the null hypothesis of no structural change against the alternative hypothesis of a single shift of 
unknown timing. We also apply these tests for stability of the short-run parameters, using the three different test statistics: Sup-F, Mean-F and Exp-F. In contrast to the $L_{c}$ test, these tests require trimming from the ends of the sample. The $p$ - and critical values for all the stability tests come from parametric bootstrapping, therefore avoiding the use of asymptotic distributions.

Table 3 reports the results of the parameter stability test for both the real house price and real GDP per capita. These parameter tests exhibit non-standard asymptotic distributions and the critical values come from Andrews (1993) and Andrews and Ploberger (1994). We obtain the critical and $p$-values using the parametric bootstrap asymptotic distribution constructed by means of Monte Carlo simulation using 2,000 samples generated from a VAR model with constant parameters to avoid the use of asymptotic distributions (Andrews, 1990). We must trim from both ends of the sample for the Sup-F, Mean-F and Exp-F tests and following Andrews (1993), we trim 15 percent from each end. Thus, we apply these tests to the fraction of the sample between $(0.15,0.85)$ percentiles. We calculate the $L_{c}$ tests for each equation separately by applying the FM-OLS estimator of Phillip and Hansen (1990). We also report the system $L_{c}$ statistic for the unrestricted VAR(2) model.

Hansen (1990) explains that the three tests Sup-F, Mean-F, and Exp-F suggested by Andrew and Ploberger (1994) test the same null hypothesis, but differ in the choice of their alternative hypotheses. The choice of which test statistic to apply depends on the purpose of the test. The Sup-F tests whether a swift shift in regime occurs, while the Mean-F and Exp-F test the gradual stability of the model over time and assumes that parameters follow a Martingale process. Table 3 reports the results of the Sup-F, Mean-F, and Exp-F tests, showing that all tests reject the null hypothesis of parameter constancy at the 1-percent level for the real house price equation, providing strong evidence of parameter non-constancy in the real house price equation of the VAR(2) model. The Sup-F and Exp-F tests reject the null 
hypothesis of parameter constancy at the 1-percent level and Mean-F rejects the null at the 5percent level for real GDP per capita equation. Therefore, significant evidence exists of parameter non-constancy in the real GDP per capita equation.

According to the results in Table 3, the $L_{c}$ statistic cannot reject the null hypothesis of parameter constancy for both the real house price and real GDP per capita equations at the 5-percent level. Therefore, we conclude that the real house price and real GDP per capita equations exhibit stable long-run parameters and also implying that cointegration exists between the two variables. The system $L_{c}$ statistic results, however, shows that an unstable VAR model exists at the 5-percent level. Thus, we conclude that VAR system exhibits unstable short-run parameters. Investigating the causal relationship between the real house price and real GDP per capita, using the short-run parameters of the differenced or cointegrated VAR, therefore, can lead to meaningless results with biased inference and inaccurate forecasts and the temporal (Granger) causality test will show sensitivity to changes in the sample period. Overall, the parameter stability test results show that the cointegrated VAR model possesses constant long-run parameters, but unstable short-run parameters, suggesting the existence of structural changes.

To check for the robustness of long-run stability of the parameters, we also perform the Johansen $(1988,1991)$ cointegration test to determine whether the real house price and real GDP per capita cointegrate with each other. The test results show evidence of no cointegration between the real house price and real GDP per capita, implying that the real house price and real GDP per capita do not maintain a long-run relationship in the levels. Appendix B reports the results for brevity. Based on the cointegration results, the $L_{c}$ test results implied possible cointegration between the real house price and real GDP per capita, while the Johansen (1988, 1991) cointegration test results showed evidence of no cointegration between the two series. Therefore, these conflicting conclusions caused us to 
estimate the cointegration equation between the real house price and real GDP per capita based on the (FM-OLS) estimator. That is, we estimate the following relationship:

$$
y_{R G D P C, t}=\alpha+\beta \cdot y_{R H P, t}+\varepsilon_{t} .
$$

Table 4 reports the results of the various parameter stability tests. The NyblomHansen $L_{c}$ test fails to reject the null hypothesis of cointegration at the 5-percent level. The Mean-F and Exp-F tests fail to reject the null hypothesis of unchanging parameters in the cointegration equation. This suggests that we do not find evidence of any gradual shifting of the parameters of the cointegration equation. Finally, the Sup-F test, however, suggests a onetime shift in the cointegration relationship. Therefore, we observe both short- and long-run instability, motivating the rolling-window Granger-causality tests.

Figures 1 and 2 plot the bootstrap p-values of the rolling test statistics and the magnitude of the effect of each series on the other. Non causality in each rolling subsample estimate is evaluated at a 10-percent level to guard against the low power of the test. Panels A and B of Figure 1 show that the $p$-values change substantially over the sample. In Panel A, the null hypothesis that the real house price does not have predictive power for real GDP per capita is not rejected at the 10-percent level during some parts of the sample and the null hypothesis that real GDP per capita does not have predictive power for the real house price is also not rejected at the10-percent level in other parts of the sample, where the $p$-values exceed 0.1. We can reject the null hypothesis that the real house price does not Granger cause real GDP per capita at the 10-percent level in almost all quarters from 1966:Q3 to 1974:Q1, from 1981:Q3 to 1985:Q1, from 1997:Q1 to 1999:Q2, and from 2001:Q3 to 2006:Q3. ${ }^{6}$ Also, we can reject the null hypothesis that real GDP does not Granger cause the real house price in

\footnotetext{
${ }^{6}$ The dating of findings from the rolling-window analysis requires the selection of a specific quarter. We choose to graph our findings where the given date represents the mid-point of the 28 quarter window. For example, a window that runs from 2005:Q2 to 2012:Q1, we date as 2008:Q4. In practice, we could choose any point from the beginning to the end of the window sample period. The only difference between the different choices is the relationship of that choice to the actual business cycle. Readers need to keep this in mind when interpreting the findings.
} 
almost all quarters from 1969:Q4 to 1971:Q2, from 1976:Q3 to 1980:Q2, and 2004:Q3 to 2008:Q3.

Comparing these two sets of findings, we can make the following observations. First, for the first (1969:Q4 to 1971Q2) and third (2004:Q3 to 2008:Q3) time periods whereby real GDP per capita Granger causes the real house price, we see that two periods of time (1966Q3 to 1974:Q1 and 2001:Q3 to 2006:Q3) whereby the real house price granger causes real GDP per capita begin before the Granger causality from real GDP per capita to the real house price. Second, real GDP per capita Granger causes the real house price in 1976:Q3 to 1980:Q2, which precedes the period whereby the real house price Granger causes real GDP per capita in 1981:Q3 to 1985:Q1. Finally, the real house price Granger causes real GDP per capita about 65 percent more often than real GDP per capita causes the real house price at the 10-percent level.

Focusing on the causality running from the real house price to real GDP per capita, 1966:Q3 to 1974:Q1 just precedes the 1973 oil crisis. Hamilton (2003, 2009) argues that oilprice-shocks proximately caused most post-WWII recessions. ${ }^{7}$ The 1981:Q3 to 1985:Q3 period proves coincident with, and lags, the severe recession in the early 1980s. Finally, the 1997:Q1 to 1999:Q2 and the 2001:Q3 to 2006:Q3 periods precede the recessions in the early 2000s and the most recent Great Recession.

A brief period of economic expansion occurred in 1975 as the real house price began to recover with several market innovations following in the form of financial reforms in the early 1980s, which further influenced the housing market (Campbell and Hercowitz, 2005). The 1980s recession is characterized by a financial industry crisis during which banks implemented various financial innovations. Mortgage market liberalization led to a

\footnotetext{
${ }^{7}$ Remember that we choose the midpoint of the rolling window in identifying all of these results. Thus, readers need to exercise caution in the interpretations offered.
} 
significant reduction in equity requirements associated with collateral borrowing (Campbell and Hercowitz, 2005). Dynan et al., (2006) further explain that several developments in the credit market probably improved households' ability to borrow, hence, decreasing the fraction of credit constrained households. At the same time, however, the credit market developments increased the sensitivity to fluctuations in economic conditions (tax reform implemented in 1986), supporting the causality running from the real house price to real GDP per capita during this period. After a period of economic expansion in the 1980s, the Gulf War and the 1990 oil-price increase weakened the economy, leading to a period of brief slowdown in economic growth. Finally, the Great Recession followed the financial crisis and the collapse of the U.S. housing market in 2006 and 2007, affecting greatly global banking systems. Prior to the financial crisis the economy experienced low interest rates and increased inflow of foreign funds. This created easy credit conditions, leading to a housing market boom and increased consumption financed by debt. In 2007, the house price started to decline, resulting in homeowners struggling to refinance when their mortgages reset the mortgage interest rate. Delinquencies and defaults of mortgages increased dramatically, notably for the subprime borrowers. The results support the view that the real house price lead real GDP per capita prior to the resulting financial crisis and Great Recession.

Panels A and B of Figure 2 show that the effects of the real house price on real GDP per capita and of real GDP per capita on the real house price, respectively. Panel A of Figure 2 indicates that the sum of the coefficients of the real house price significantly affects real GDP per capita in seven different periods. The three longest periods include positive effects from 1974:Q1 to 1978:Q4 and 2000:Q4 to 2008:Q4 and a negative effect from 1981:Q2 to 1985:Q1. Panel B of Figure 2 indicates that he sum of the coefficients of real GDP per capita significantly affects the real house price in five different periods. Positive effects exist for 
1966:Q3 to 1971:Q4, 1977:Q4 to 1980:Q4, and 1993:Q1 to 2000:Q1 while negative effects occur from 1988:Q4 to 1989:Q4 and 2006:Q1 to 2008:Q2.

These results lead to a couple of observations. First, the significant effect of the sum of coefficients of the real house price on real GDP per capita lead the significant effect of the sum of coefficients of real GDP per capita on the real house price in three of these cases. That is, the positive effects of the real house price on real GDP per capita from 1974:Q1 to 1978Q4 and 2000:Q4 to 2008:Q4 lead the positive and negative effects of real GDP per capita on the real house price from 1977Q4 to 1980:Q4 and 2006:Q1 to 2005:Q2, respectively. Further, the negative effect of the real house price on real GPD per capita from 1981:Q2 to 1985:Q1 lead the negative effect of real GDP per capita on the real house price from 1988:Q4 to 1989:Q4. Second, in one instance, the positive effect of real GDP per capita from 1993Q1 to 2000:Q1 leads the positive effect of the real house price on real GDP per capita from 2000:Q4 to 2008:Q4. Finally, 51 percent of the quarters report a significant sum of the coefficients that the real house price affects real GDP per capita - about 34 percent positive and 16.5 percent negative -- while 49 percent of the quarters report a significant sum of the coefficients that real GDP per capita affects the real house price - about 39 percent positive and 10 percent negative.

\section{Conclusion}

The recent global financial crisis, which originated from the subprime crisis in the U.S., recently led many researchers to focus on the housing market and its effect on the economy. This paper investigates the causal relationship between the real house price and real GDP per capita. We use a bootstrap full-sample and sub-sample rolling-window approach. The rollingwindow approach allows the causal relationship between the two series to vary over time, instead of assuming a single unchanging relationship over the full-sample period. We use quarterly time series data from 1963:Q1 to 2012:Q2 from the U.S. This sample period covers 
known economic expansions and recessions, as well as market innovations that may imply different responses during different sub-samples.

This paper considers the possible presence of structural changes. Tests for parameter constancy applied to examine the stability of the estimated VAR model show both short- and long-run instability. Thus, the full-sample causality test will not provide reliable findings. We use the time-varying (bootstrap) rolling-window approach to examine the causal relationship between the real house price and real GDP per capita.

Using a rolling window of 28 quarters, results show that significant causality from the real house price to real GDP per capita occurs more frequently than significant causality from real GDP per capita to the real house price. In addition, the positive cumulative effect of the real house price on RGPD per capita occurs twice as frequently as the negative cumulative effect. The positive cumulative effect of real GDP per capita on the real house price occurs four- times as often as the negative cumulative effect.

These results show that while the real house price generally leads real GDP per capita, both during expansions and recessions, significant feedback effects from the real GDP per capita onto the real house price. These findings occur especially during periods of volatility such as the 1973 and 1979 oil price hikes, the early 1980s recession, the brief recession in the 1990s, as well as, the recent financial crisis and Great Recession.

The experience of the financial crisis and Great Recession provides the period with the most vigorous response of real GDP per capita to the real house price. The real house price Granger causes real GDP per capita for an extended period prior to the Great Recession. In addition, the cumulative effect of the real house price on real GDP per capita proves positive and of long duration. Moreover, real GDP per capita Granger causes the real house price with some lag after the observation that the real house price Granger causes real GDP 
per capita. Finally, the cumulative effect of real GDP per capita on the real house price proves negative during this period.

Finally, this paper began with the proposition that housing prices play an important role in the growth and decline of the macroeconomy. Miller et al. (2011) argues “... the strong housing market during the crash of the stock market in 2001 might have helped save the US economy from a more serious recession, and recent cooling of the housing market has triggered a recession since December 2007.” (p. 523). Our findings support this statement. To wit, we find strong evidence of a causal link from the real house price to real GDP per capita in the financial crisis and Great Recession. Moreover, the cumulative effect of the real house price on real GDP per capita proves positive - a lower the real house price causing lower real GDP per capita. During the 2001 recession, we find that, once again, strong evidence exists of a causal link from the real house price to real GDP per capita. But in this instance, the cumulative effect of the real house price on real GDP per capita proved negative - a higher real house price causing a lower real GDP per capita.

\section{References}

Abdallah, C. S., and Lastrapes, W. D., 2012. Home equity lending and retail spending: Evidence from a natural experiment in Texas. American Economic Journal: Macroeconomics 4, 94-125.

Andrews, D. W. K., 1993. Tests for parameter instability and structural change with unknown change point. Econometrica 61, 821-856.

Andrews, D. W. K., and Ploberger, W., 1994. Optimal tests when a nuisance parameter is present only under the alternative. Econometrica 62, 1383-1414.

Aoki, K., Proudman, J., and Vlieghe, G., 2004. House prices, consumption, and monetary policy: A financial accelerator approach. Journal of Financial Intermediation 13, 414-435.

Balcilar, M., Ozdemir, Z. A., and Arslanturk, Y. (2010) Economic growth and energy consumption causal nexus viewed through a bootstrap rolling window. Energy Economics, 32(6),1398-1410. 
Belsky, E., and Prakken, J. 2004. Housing wealth effects: Housing's impact on wealth accumulation, wealth distribution, and consumer spending. Working Paper W04-13, Harvard University Joint Center for Housing Studies.

Bernanke, B. S., 2008. Housing, mortgage markets, and foreclosures. Remarks at The Federal Reserve System Conference on Housing and Mortgage Markets, Washington, D.C.

Buiter, W. H., 2008. Housing wealth isn't wealth. Working Paper 14204, London School of Economics and Political Science.

Campbell, J. R., and Hercowitz, Z., 2005. The Role of Collateralized Household Debt in Macroeconomic Stabilization. National Bureau of Economic Research Working Paper 11330.

Campbell, J., and Cocco, J., 2007. How do house prices affect consumption? Evidence from micro data. Journal of Monetary Economics 54, 591-621.

Carroll, C. D., 2004. Housing wealth and consumption expenditure. Paper presented at Academic Consultants' meeting of the Board of Governors of the Federal Reserve System, January 30.

Carroll, S. D., Otsuka, M., and Slacalek, J., 2011. How large are housing and financial wealth effects? A new approach. Journal of Money, Credit and Banking 43, 55-79.

Case, K., Shiller, R., and Quigley, J., 2005. Comparing wealth effects: The stock market versus the housing market. Advances in Macroeconomics, 5:1-32.

Case, K., Quigley, J., and Shiller, R., 2013. Wealth effects revisited: 1975-2012. NBER Working Paper No. 18667.

Chui, L. H. T., and Chau, K. W., 2005. An empirical study of the relationship economic growth, real estate prices and real estate investments in Hong Kong. Surveying and Built Environment 16(2), 19-32.

Demary, M., 2010. The interplay between output, inflation, interest rates and house prices: International Evidence. Journal of Property Research, 27(1):1-17.

Dynan, K. E., Elmendorf, D. W., and Sichel, D. E., 2006. Can financial innovation help to explain the reduced volatility of economic activity? Journal of Monetary Economics 53(1): 123-50.

Girouard, N., Kennedy, M., den Noord, P., and André, C., 2006. Recent house price developments: The role of fundamentals. OECD Economics Department Working Paper No.475.

Granger, C. W. J., 1969. Investigating causal relations by econometric models and cross spectral methods. Econometrica 37, 424-438.

Guerrieri, L., and Iacoviello, M., 2013. Collateral constraints and macroeconomic asymmetries. Mimeo, Boston College. 
Hacker, R. S., and Hatemi-J, A., 2006. Tests for causality between integrated variables using asymptotic and bootstrap distributions: theory and application. Applied Economics 38, 1489-1500.

Hamilton, J. D., 2003. What Is an Oil Shock? Journal of Econometrics 113, 363-398.

Hamilton, J. D., 2009. Causes and Consequences of the Oil Shock of 2007-08. Brookings Papers on Economic Activity (Spring), 215-261.

Hansen, B. E., 1992. “Tests for parameter instability in regressions with I(1) processes”, Journal of Business and Economic Statistics 10, 321-336.

Iacoviello, M., 2005. House prices, borrowing constraints, and monetary policy in the business cycle. American Economic Review, 95:739-764.

Iacoviello, M., 2010. Housing in DSGE models: Findings and new directions. In Bandt, O. de; Knetsch, Th.; Peñalosa, J.; Zollino, F. (Eds.), Housing Markets in Europe: A Macroeconomic Perspective, Berlin, Hidelberg: Springer-Verlag, 3-16.

Iacoviello, M., 2011. Housing wealth and consumption. International Encyclopedia of Housing and Home, Elsevier.

Iacoviello, M., and Neri, S., 2010. Housing market spillovers: Evidence from an estimated DSGE model. American Economic Journal: Macroeconomics 2, 125-164.

Johansen, S., 1991. Estimation and hypothesis testing of cointegration vectors in Gaussian vector autoregressive models. Econometrica 59, 1551-1580.

Koutris, A., Heracleous, M. S., and Spanos, A., 2008. Testing for nonstationarity using maximum entropy resampling: A misspecification testing perspective. Econometric Reviews 27, 363-384.

Leamer, E. E., 2007. Housing IS the business cycle. Proceedings, Federal Reserve Bank of Kansas City, 149-233.

Liu, Z., Wang, P., and Zha, T., 2013. Land-price dynamics and macroeconomic fluctuations. Econometrica 81, 1147-1184.

Lustig, H., and Van Nieuwerburg, S., 2008. How much does household collateral constrain regional risk sharing? Working Paper 10505, University of Chicago.

MacKinnon, J. G., Haug, A. A., and Michelis, L., 1999. Numerical distribution functions of likelihood ratio tests for cointegration. Journal of Applied Econometrics 14, 563-577.

Mantalos, P., 2000. A graphical investigation of the size and power of the granger-causality tests in integrated-cointegrated VAR systems. Studies in Non-Linear Dynamics and Econometrics 4, 17-33. 
Mantalos, P., and Shukur, G., 1998. Size and power of the error correction model cointegration test. A bootstrap approach. Oxford Bulletin of Economics and Statistics 60, 249-255.

Mian, A., and Sufi, A., 2011. House prices, home equity-based borrowing, and the us household leverage crisis. American Economic Review 101, 2132-2156.

Mian, A. R., Rao, K., and Sufi, A., 2012. Household balance sheets, consumption, and the economic slump. Mimeo, Princeton University.

Midrigan, V., and Philippon, T., 2011. Household leverage and the recession. NBER working paper no. 16965.

Miller, N., Peng L., and Sklarz, M., 2011. House prices and economic growth. Journal of Real Estate Finance and Economics, 42(4): 522-541

Ng, S., and Perron, P., 2001. Lag length selection and the construction of unit root tests with good size and power. Econometrica 69, 1519-1554.

Nyblom, J., 1989. Testing for the constancy of parameters over time. Journal of the American Statistical Association 84, 223-230.

Pesaran, M. H., and Timmermann, A., 2005. Small sample properties of forecasts from autoregressive models under structural breaks. Journal of Econometrics 129, 183-217.

Phillips, P. C. B., and Perron, P., 1988. Testing for a unit root in time series regression. Biometrika 75, 335-346.

Rapach, D. E., and Staruss, J. K., 2009. Differences in housing price forecastability across U.S. states. International Journal of Forecasting 25, 351-372

Shukur, G., and Mantalos, P., 1997a. Size and power of the RESET test as applied to systems of equations: A boot strap approach. Working paper 1997:3, Department of Statistics, University of Lund, Sweden.

Shukur, G., and Mantalos, P., 1997b. Tests for Granger causality in integrated-cointegrated VAR systems. Working paper 1998:1, Department of Statistics, University of Lund, Sweden.

Shukur, G., and Mantalos, P., 2000. A simple investigation of the Granger-causality test in integrated-cointegrated VAR systems. Journal of Applied Statistics 27, 1021-1031.

Simo-Kengne, B. D., Bittencourt, M., and Gupta, R., 2012. House prices and economic growth in South Africa: Evidence from provincial-level data. Journal of Real Estate Literature 20, 97-117.

Stock, J. H., and Watson, M. W., 1996. Evidence on structural instability in macroeconomic time series relations, Journal of Business \& Economic Statistics, American Statistical Association 14, 11-30. 
Toda, H. Y., and Phillips, P. C. B., 1993. Vector autoregressions and causality. Econometrica $61,1367-1393$.

Toda, H. Y., and Phillips, P. C. B., 1994. Vector autoregression and causality: A theoretical overview and simulation study. Econometric Reviews 13, 259-285.

Toda, H. Y., and Yamamoto, T., 1995. Statistical inference in vector autoregressions with possibly integrated processes. Journal of Econometrics 66, 225-250.

Zeileis A, Leisch F, Hornik K, and Kleiber C., 2005. Monitoring structural change in dynamic econometric models. Journal of Applied Econometrics 20, 99-121.

Zhou, X., And Carroll, C. D., 2012. Dynamics of wealth and consumption: new and improved measures for U.S. states. The B.E. Journal of Macroeconomics 12, 1-44. 
Table 1A: $\quad Z_{\alpha}$ unit root test results Phillip and Perron

\begin{tabular}{lcccc}
\hline & \multicolumn{2}{c}{ Level } & \multicolumn{2}{c}{ First differences } \\
\hline Series & $Z_{\alpha}^{\mathrm{a}}$ & $Z_{\alpha}^{\mathrm{b}}$ & $Z_{\alpha}$ & $Z_{\alpha}$ \\
\hline Real House Price & -1.630 & -1.495 & $-16.357^{*}$ & $-16.312^{*}$ \\
Real GDP per Capita & -1.617 & -2.151 & $-10.493^{*}$ & $-10.577^{*}$ \\
\hline
\end{tabular}

Note: * indicates significance at the 1-percent level.

${ }^{a}$ A constant is included in the test equation; one-sided test of the null hypothesis that a unit root exists; 1 , 5 and $10 \%$ significance critical value equals $-3.463,-2.876,-2.574$, respectively.

${ }^{\mathrm{b}} \mathrm{A}$ constant and a linear trend are included in the test equation; one-sided test of the null hypothesis that a unit root exists; 1,5 and $10 \%$ critical values equals $-4.005,-3.432,-3.140$, respectively

Table 1B: $\quad \mathrm{M}_{\alpha}$ unit root test results Ng- Perron

\begin{tabular}{lcccc}
\hline & \multicolumn{2}{c}{ Level } & \multicolumn{2}{c}{ First Difference } \\
\hline Series & $M Z_{\alpha}^{a}$ & $M Z_{\alpha}^{b}$ & $M Z_{\alpha}$ & $M Z_{\alpha}$ \\
\hline Real House Prices & 0.037 & -4.044 & $-17.136^{*}$ & $-25.193^{*}$ \\
Real GDP per Capita & 1.132 & -10.197 & $-51.156^{*}$ & $-60.969^{*}$ \\
\hline
\end{tabular}

Note: * indicates significance at the 1-percent level.

${ }^{a}$ A constant is included in the test equation; one-sided test of the null hypothesis that a unit root exists; 1 , 5 and $10 \%$ significance critical value equals $-13.800,-8.100,-5.700$, respectively.

${ }^{\mathrm{b}} \mathrm{A}$ constant and a linear trend are included in the test equation; one-sided test of the null hypothesis that a unit root exists; 1,5 and $10 \%$ critical values equals $-23.800,-17.300,-14.200$, respectively.

Table 2: $\quad$ Full Sample Granger Causality Tests

\begin{tabular}{|c|c|c|c|c|}
\hline & \multicolumn{2}{|c|}{$\begin{array}{c}\mathrm{H}_{0}: \text { RHP does not Granger } \\
\text { cause REAL GDP per } \\
\text { capita }\end{array}$} & \multicolumn{2}{|c|}{$\begin{array}{c}\mathrm{H}_{0} \text { : REAL GDP per capita } \\
\text { does not Granger cause } \\
\text { RHP }\end{array}$} \\
\hline & Statistics & $p$-value & Statistics & $p$-value \\
\hline Bootstrap LR Test & 6.815 & $0.030 * *$ & 7.307 & 0.148 \\
\hline
\end{tabular}

Table 3: $\quad$ Parameter Stability Tests in $\operatorname{VAR}(2)$ Model

\begin{tabular}{lcccccc}
\hline & \multicolumn{2}{c}{$\begin{array}{c}\text { Real House Price } \\
\text { Equation }\end{array}$} & $\begin{array}{c}\text { Real GDP per Capita } \\
\text { Equation }\end{array}$ & \multicolumn{2}{c}{ VAR(2) System } \\
\cline { 2 - 7 } & Statistics & $\begin{array}{c}\text { Bootstrap } \\
\boldsymbol{p} \text {-value }\end{array}$ & Statistics & $\begin{array}{c}\text { Bootstrap } \\
\boldsymbol{p} \text {-value }\end{array}$ & Statistics & $\begin{array}{c}\text { Bootstrap } \\
\boldsymbol{p} \text {-value }\end{array}$ \\
\hline Sup-F & $31.09 * * *$ & $<0.01$ & $34.47 * * *$ & $<0.01$ & $18.99 * * *$ & $<0.01$ \\
Mean-F & $15.06 * * *$ & $<0.01$ & $11.88^{* * *}$ & 0.01 & $45.10^{* * *}$ & $<0.01$ \\
Exp-F & $12.01 * * *$ & $<0.01$ & $13.12^{* * *}$ & $<0.01$ & $19.95^{* * *}$ & $<0.01$ \\
$\boldsymbol{L}_{\boldsymbol{c}}$ & 0.61 & 0.55 & 0.69 & 0.49 & $3.12^{* * *}$ & 0.01 \\
\hline
\end{tabular}

Note: We calculate $p$-values using 2,000 bootstrap repetitions. ${ }^{* * *}$ indicate significance at the 1-percent level.

Table 4: $\quad$ Parameter Stability Tests in Long-Run Relationship FM-OLS

\begin{tabular}{lllll}
\hline & Sup-F & Mean-F & Exp- $\boldsymbol{F}$ & $\boldsymbol{L}_{\boldsymbol{c}}$ \\
\hline RGDPPC $=\boldsymbol{\alpha}+\boldsymbol{\beta} *$ RHP & 603.62 & 199.96 & 297.01 & 0.16 \\
Bootstrap $\boldsymbol{p}$ value & $<0.01$ & 1.00 & 1.00 & 0.72 \\
\hline
\end{tabular}


Figure 1A: Rolling Window Bootstrap p-Value: Null that the Real House Price Does Not Granger Cause Real GDP per Capita

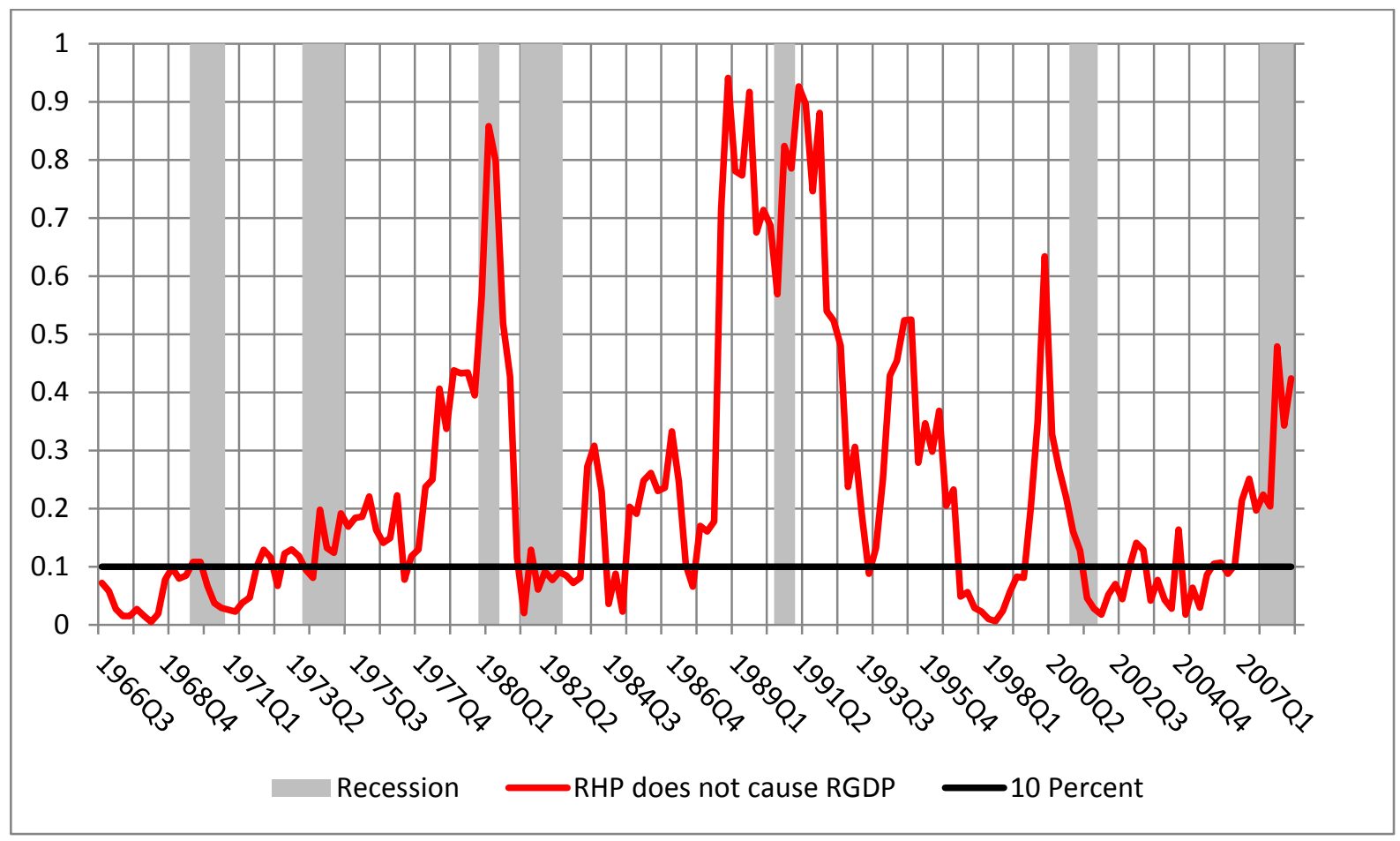

Figure 1B: Rolling-Window Bootstrap $p$-Value: Null that Real GDP per Capita Does Not Granger Cause Real House Price

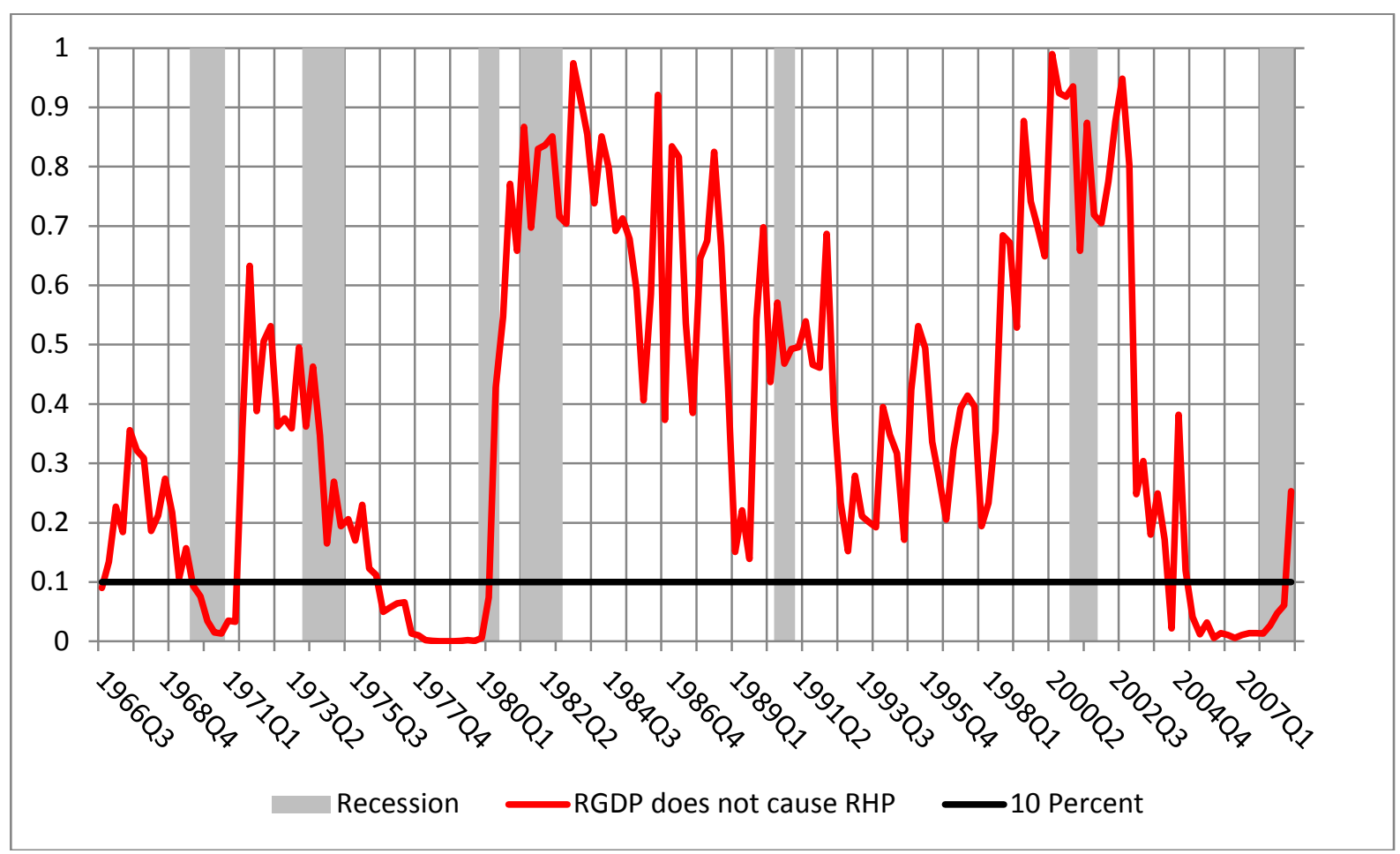


Figure 2A: Rolling-Window Bootstrap Estimate: Sum of Coefficients that the Real House Price on Real GDP per Capita

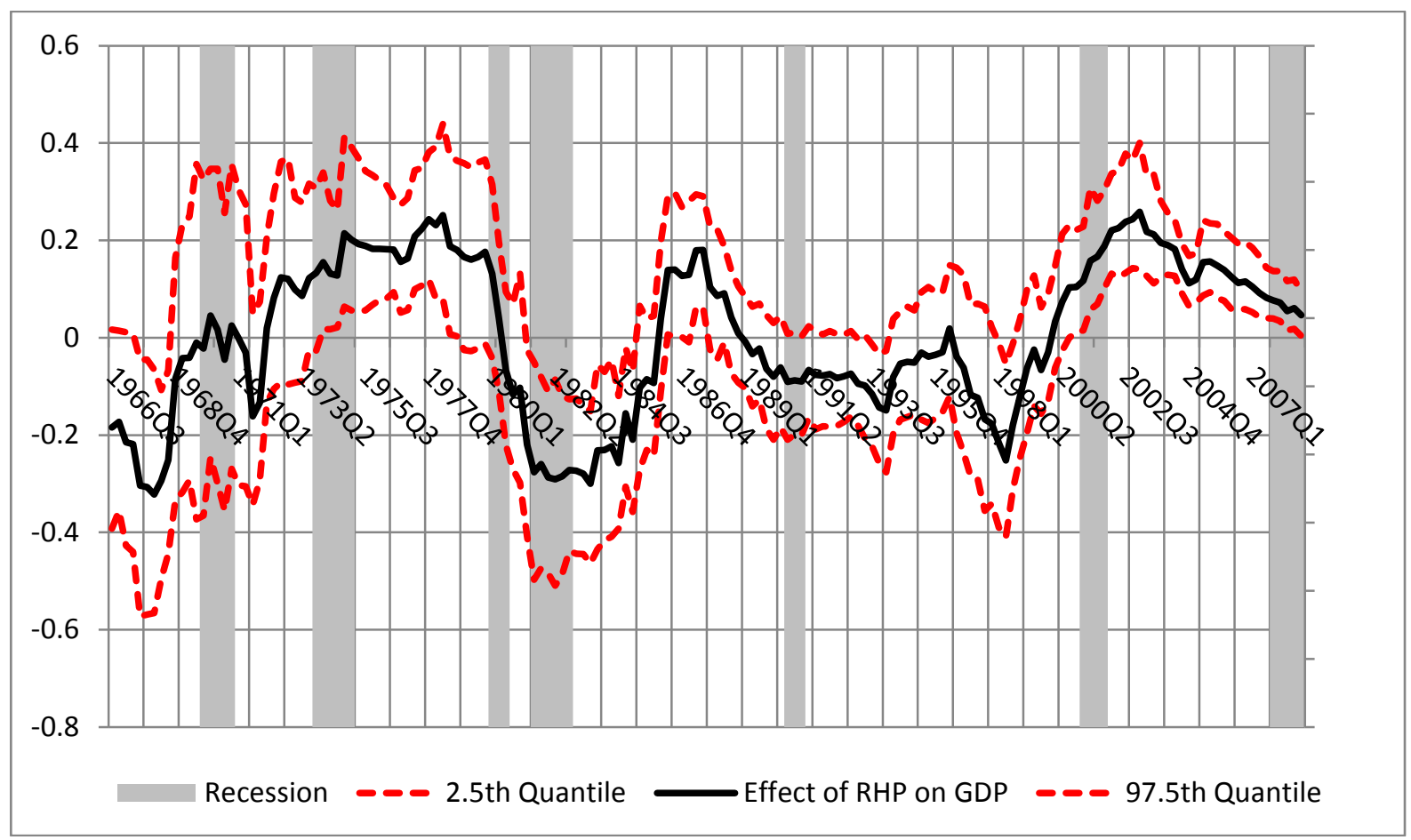

Figure 2B: Rolling-Window Bootstrap Estimate: Sum of Coefficients that Real GDP per Capita on the Real House Price

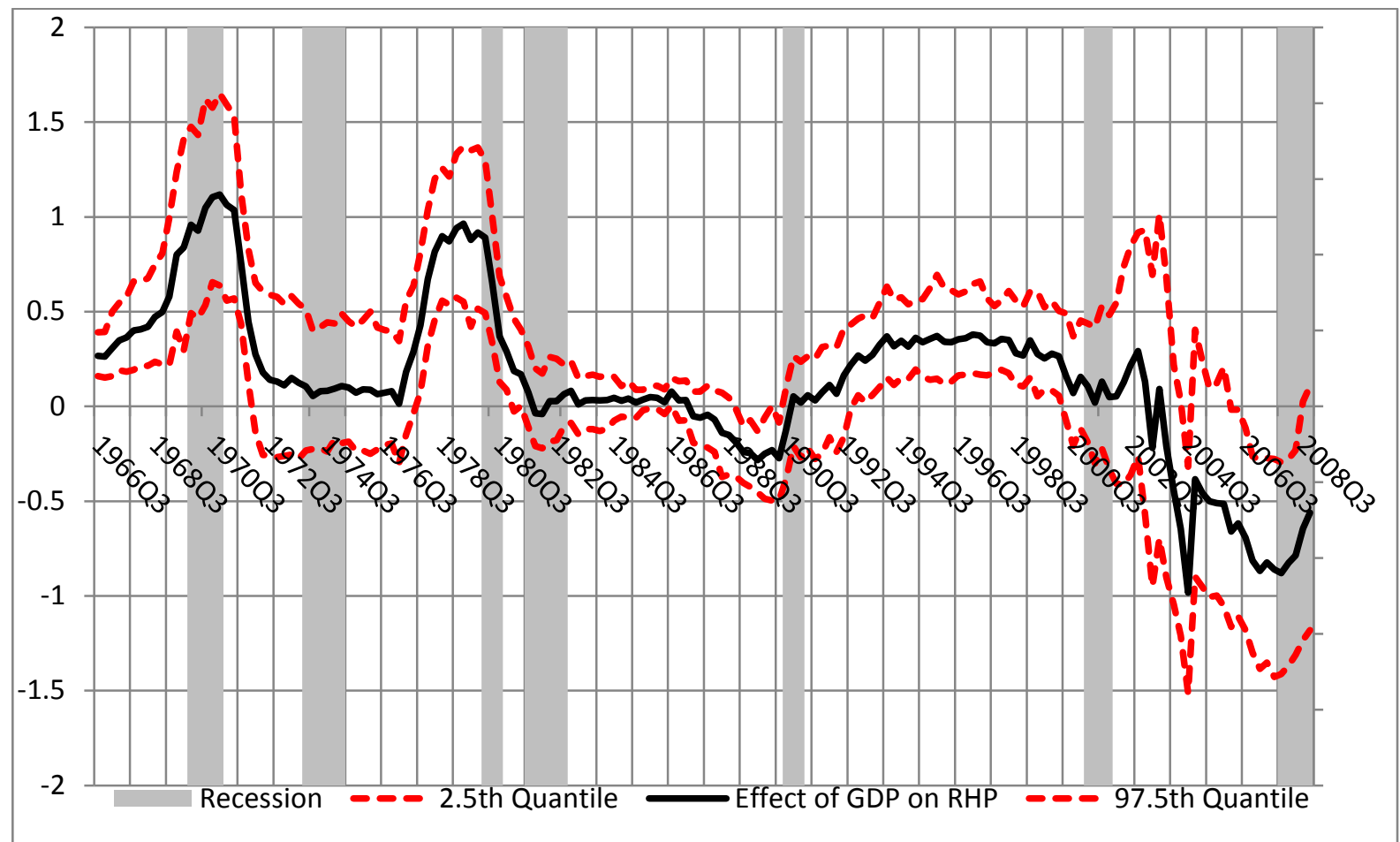




\section{Appendix A:}

Figure A1: Real House Price

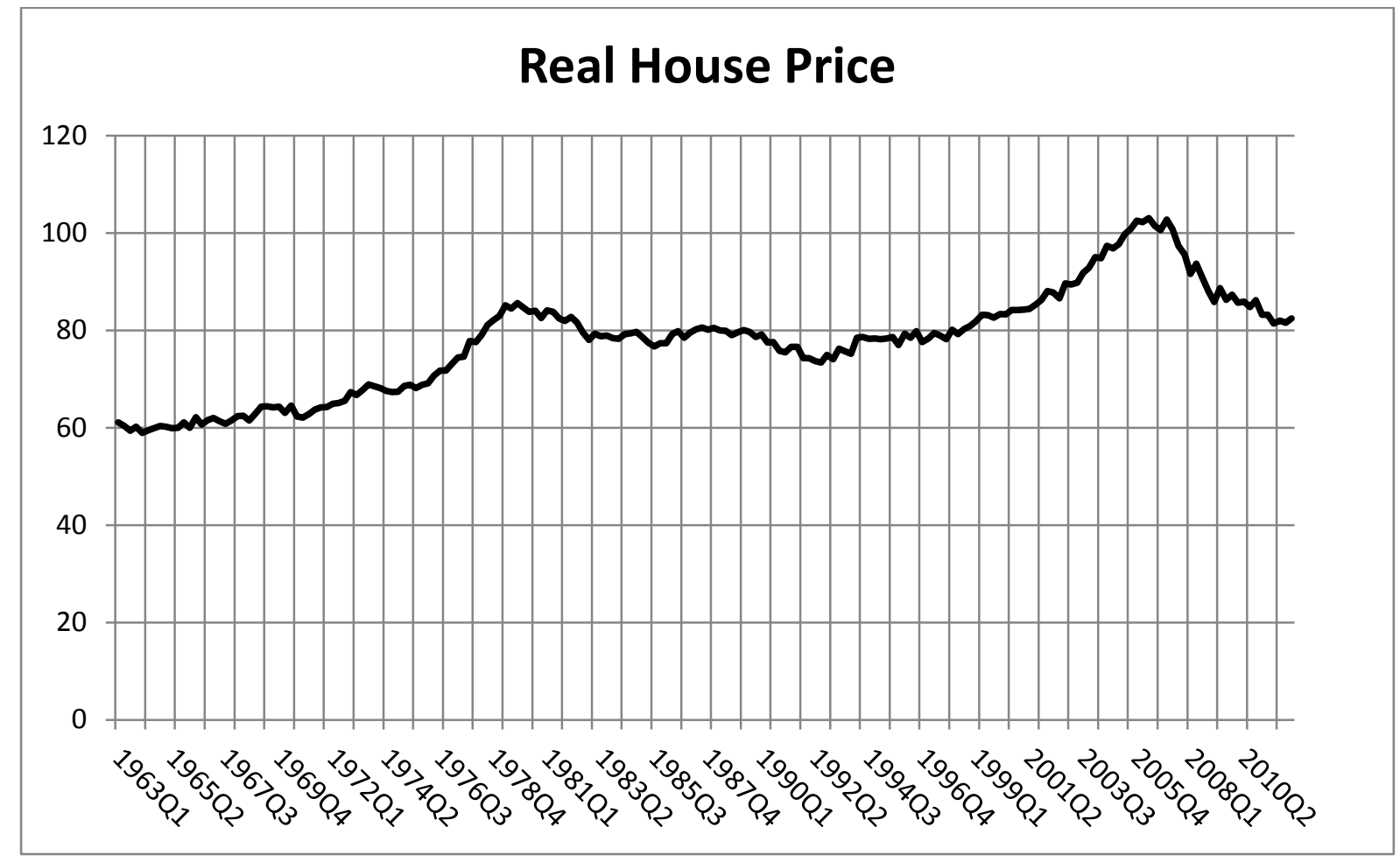

Figure A2: Real GDP per Capita

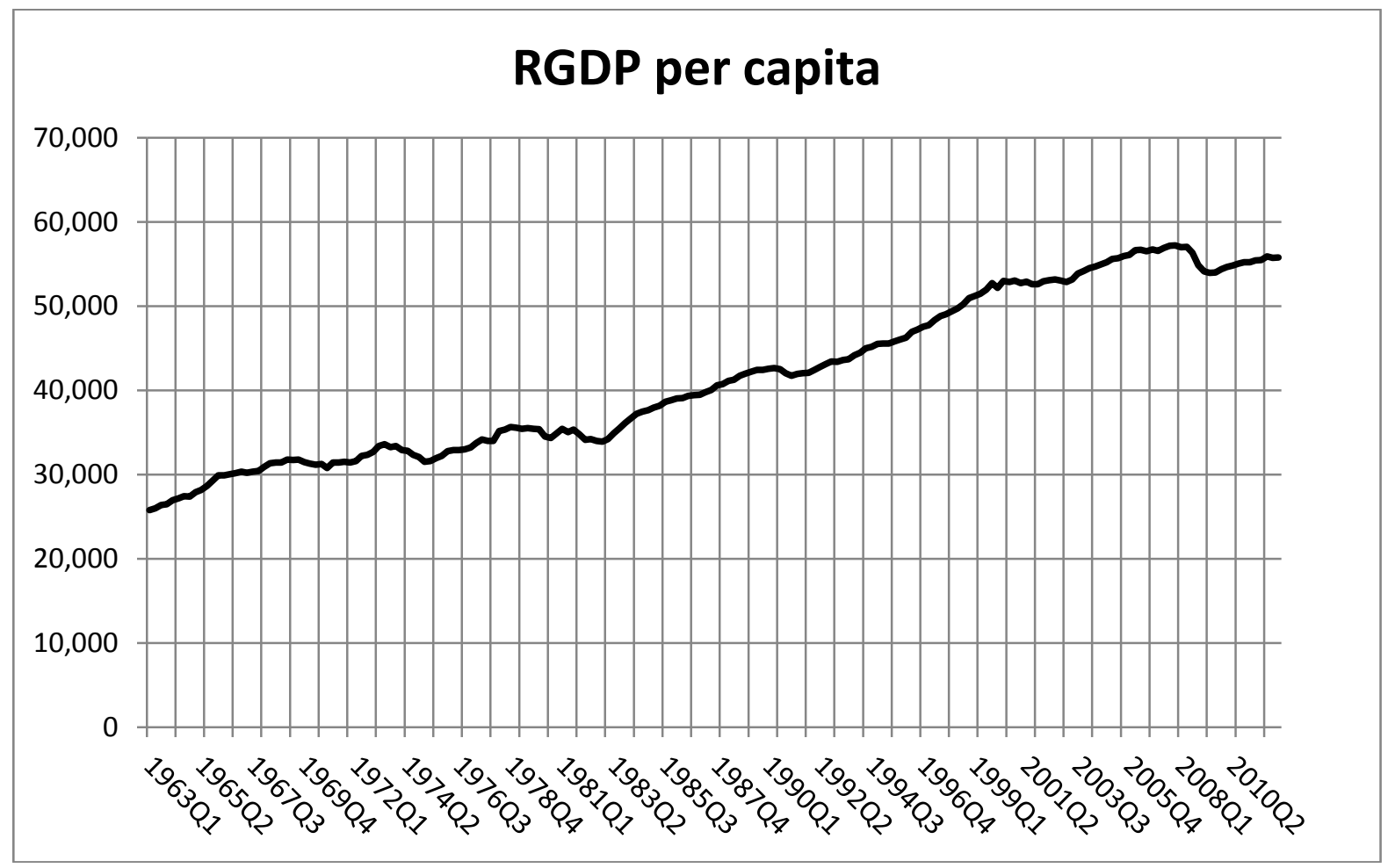




\section{Appendix B:}

Table B1: Johansen's Cointegration test results

\begin{tabular}{lcccc}
\hline Series & $\mathbf{H}_{\mathbf{0}}{ }^{\mathbf{a}}$ & $\mathbf{H}_{\mathbf{1}}$ & Trace Statistic & $\begin{array}{c}\text { Maximum-Eigen } \\
\text { Statistic }\end{array}$ \\
\hline \multirow{2}{*}{ RHP and RGDP } & $r=0$ & $r>0$ & 4.23 & 4.08 \\
& $r \leq 1$ & $r>1$ & 0.14 & 0.14 \\
\hline
\end{tabular}

Notes: ${ }^{* *}$ indicates significance at the 5 percent level.

a One-sided test of the null hypothesis $\left(\mathrm{H}_{0}\right)$ that the variables are not cointegrated against the alternative $\left(\mathrm{H}_{1}\right)$ of at least one cointegrating relationship. The critical values are taken from MacKinnon et al., (1999) with 5 percent critical values equal to 15.49 for testing $r=0$ and 3.84 for testing $r \leq 1$ for the Trace test. The corresponding values for the Maximum Eigenvalue tests are 14.26 and 3.84 . 